\title{
As Categorias Jurídicas e o Direito Público.
}

\author{
José Cretella Júnior \\ Livre Docente de Direito Administrativo na \\ Faculdade de Direito da Universidade de \\ São Paulo.
}

SumÂrio: 1. O problema. 2. Primado civilístico. 3. Reformulação dos moldes publicísticos. 4. Método de trabalho. 5. Aplicação do método a alguns institutos. 6. Conclusão.

\section{O problema.}

O direito público é, sem dúvida, de remota existência mas, como ramo autônomo e com princípios bem delineados está bem longe de alcançar a estruturação privatística.

Ao passo que o direito privado tem atrás de si milenar elaboração doutrinária, o direito público nem bem ensaia os primeiros passos dentro da primeira centúria de vida.

Em seu processo de doutrinária, ocorrem os mais variados defeitos técnicos, o que se reflete na identificação dos institutos, no enquadramento científico da realidade, bem como na rotulação terminológica, com repercussões negativas no processus nomogenético e na orientação das grandes teses jurisprudenciais.

Diante do caso concreto a ser resolvido hesita ainda a maioria de nossos magistrados e doutrinadores, ainda 
sob o impacto dos princípios informativos do direito privado.

Tem-se muitas vêzes conhecimento do instituto, chegase mesmo a institui-lo em suas linhas gerais, mas falta no campo jurídico público a exata cobertura doutrinária e a respectiva tradição jurisprudencial para a tomada certa de posição.

Problemas, simples em si, por receberem tratamento inadequado resolvem-se de maneira incorreta, afastadas que estão suas normas diretoras da moderna técnica peculiar ao direito público. Típicas questões de direito público, equacionadas em moldes privatísticos, desvirtuam-se, conduzindo a resultados desastrosos, inaceitos, portanto, pelo rigor que a ciência do direito exige. Questões de facto são apuradas com exatidão. Entendem-se os dados do problema. Aplicam-se-lhes, entretanto, fórmulas inadequadas. Falta a certa adaequatio, o uso de mensuração compatível, enfim, o equacionamento em têrmos e na linguagem do direito público.

Como proceder? Qual a orientação a seguir no trato dos institutos do direito público?

Urge que os cultores dêste ramo em que se desdobra a ciência do direito se ponham a campo, reexaminem as posições adotadas, indaguem das "formas puras" da Jurisprudência de que fala Stammler e atinjam as categorias jurídicas ${ }^{\star}$, procedendo a seguir, em sentido inverso, ou seja, partindo destas - e não dos resultados a que chegou o direito privado para a identificação das espécies que ocorrem no setor publicístico. Rejeite-se, pois, e sempre,

* Que são categorias jurídicas? A expressão é aqui entendida no sentido de formulações genéricas, in abstracto, com suas conotações essenciais, ainda não comprometidas com nenhum dos dois ramos em que se divide a ciência jurídica. Trata-se das figuras, in genere, comuns ao direito público e ao privado 
qualquer tentativa de transposição de institutos de um campo a outro.

\section{Primado Civilístico.}

Difícil, no entanto, é lutar contra uma tradição que se vem impondo há dois mil anos. Durante êsses vinte séculos aquêle povo que foi "gigante no direito privado, pigmeu no direito público" lançou a base, impondo princípios por que se moldaram todos os ramos de ciência jurídica, a partir do direito civil.

O Direito civil não é nem a raiz, nem o tronco principal da árvore jurídica, mas um dos dois ramos em que o tronco principal se subdivide. É o cadinho comum, em que se misturaram os ingredientes jurídicos. A principiar pela terminologia. É o ramo que despontou em primeiro lugar, que cresceu mais depressa e por mais tempo. Nunca, porém, o tronco mestre, do qual se foram desgalhando os outros ramos. A irradiação é sucessiva, convenhamos. Não sendo simultânea, deu a impressão de que uns ramos emergem de outros, tendo-se o direito civil como o centro primeiro de irradiação.

Roma, Idade Média, Renascimento, Tempos Modernos conspiraram contra o direito público, prestigiando a tradição privatística. Técnica, nomenclatura, princípios, institutos, regime jurídico, enfim, tudo que se elaborou para o âmbito do direito privado foi transposto para o setor do direito público.

2000 anos de direito privado contra 100 anos de direito público representam pugna bastante desigual.

Cabe ao cultor do direito público reformular a experiência jurídica à luz dos principios próprios, estremando o público do privado, submetendo a um tratamento adequado de direito público os institutos que lhe são típicos. 


\section{Reformulação dos Moldes Publicísticos.}

Até agora tem prevalecido a mentalidade privatística, que equaciona os problemas do direito público em têrmos: próprios, levando para o nôvo campo os próprios resultados alcançados. Traduz-se. Não se fala a linguagem: natural do direito público. Pede-se emprestado. Adata-se. Transpõe-se.

Dêsse modo, quando se analisa, por exemplo, o contrato do direito público ou a fundação pública, o ponto de partida é o "contrato" ou a "fundação". Mas que contrato? Que fundação? Contrato de direito privado. Fundação de direito privado.

Chega-se ao cúmulo de raciocinar-se dentro dos esquemas do direito positivo, afirmando-se: o código civil só admite e só regula a fundação de direito privado. Logo, como escapar a tão expresso pronunciamento?

Ora, tais institutos se caracterizam, no direito privado, por notas secundárias, acessórias que, é claro, se encontram ausentes no setor do direito público.

O resultado é um apenas: nega-se o contrato e a fundação do direito público diante da ausência das conotações acessórias, presentes nestas figuras, no campo do direito privado. Deixa-se de lado a figura pura, genérica, antes da entrada no setor bifurcado, para trabalhar-se com a figura espécie, matizada pelos traços típicos de um dos campos.

A reformulação dos moldes publicísticos está ainda por fazer-se, organizando-se um quadro panorâmico das categorias jurídicas, definindo-se a seguir in genere, uma a uma, as figuras da ciência e do direito, antes do ingresso na área privatística ou na área publicística. 
Nesse exame vestibular dos institutos, ter-se-á a cautela de separar o principal do acessório, o gênero da espécie, definindo-se de maneira sintética, mas inconfundível, a forma pura, a figura-gênero, não trabalhada por nenhum dos campos.

Duma simplicidade que salta à vista, duma importância inquestionável, não se tratou, entretanto, dêste tema nas obras especializadas da disciplina administrativa.

Por onde começar? Que método de trabalho se deve empregar? Como proceder ao reexame dos próprios quadros da ciência do direito para atingir-se a raiz primeira, no estágio indiferenciado que é a própria essência do instituto puro?

\section{Método de Trabalho.}

Não é possível, num primeiro trabalho sôbre tema tão complexo, equacionar e resolver teses de tal transcendência. Nosso objetivo é, antes de tudo, chamar a atenção dos estudiosos para o perigo das transposições de institutos de um campo a outro.

E indispensável, ao contrårio, examinar os institutos aos pares (público e privado), procedendo indutivamente, da espécie para o gênero, eliminando o acessório e trabaIhando com o principal, num depuramento continuo, até atingir-se a "forma pura", a "categoria jurídica", o molde indiferenciado, a figura do direito. E não a figura do direito privado ou a figura do direito público.

As modalidades diferenciadas dos dois campos fornecerão elementos ou subsídios para a construção do protótipo indiferenciado comum e, procedendo-se, depois, em sentido inverso, dedutivamente, é possivel descer a cada um dos campos, como meio científico de contraprova. 
Pesquisa sistemática no capítulo das pessoas (privadas e públicas), dos bens (privados e públicos), dos coniratos (privados e públicos), dos atos jurídicos (privados e públicos), das servidões (privadas e públicas), etc., irá fornecer elementos básicos para a formulação de novos problemas do direito público.

Responder-se-ão perguntas do seguinte tipo: quando uma pessoa jurídica é de direito privado e quando se enquadra no direito público? A fundação, milenarmente trabalhada pelo direito privado, é especifica dêste campo, ou existe também no âmbito do direito público? Qual o conceito genérico de fundação? A que regime jurídico se subordinam os bens privados e os bens públicos? QuaI conjunto de sinais que permite distinguir o contrato de direito privado do contrato de direito público? A figura in genere do contrato é peculiar ao direito privado ou comum a ambos os campos? Houve, realmente, uma evolução no delineamento da figura contratual ou o direito atingiu uma fase de amadurecimento científico que lhe permitiu visão mais penetrante de velhos problemas à luz de novas técnicas? $O$ ato administrativo não é o mesmo ato jurídico, diferenciado? Pode haver ato administrativo que não haja, antes, ato jurídico? E o ato jurídico privado não é também ato jurídico? $\mathrm{E}$ ambas as modalidades não se prendem a um arquétipo comum que deitou raízes em dois campos, com as necessárias transformações? O mútuo, o comodato, o depósito, o penhor não existirão igualmente no terreno do direito público? Sob que aspectos? Quais os traços in genere dêsses institutos?

\section{Aplicação do Método e Alguns Institutos.}

Examinemos, por exemplo, no capítulo das pessoas, o instituto das fundações, de raízes romanas seculares. Que 
é a fundação? Uma pessoa jurídica, sem dúvida. De direito público ou de direito privado?

Os privatistas respondem sem hesitar: a fundação é, só e só, uma pessoa jurídica de direito privado. E, categòricamente, encerram o assunto: não há fundação que não seja de direito privado. É do Código Civil. Há autores que chegam a afirmar: fundação de direito público é uma contradictio in terminis.

O problema tem de ser pôsto em outros têrmos.

Em primeiro lugar, quem nos dá o conceito de fundação não é o direito privado. Êste trabalhará com a categoria jurídica pura, amoldando-a às suas necessidades, aparelhando-a para seu campo. Tomar o instituto da fundação, estruturado durante séculos pelo direito civil, e. trasladá-lo para o campo do direito público, é o mesmo que procurar adatar a um modêlo um determinado molde, feito sob medida para outro modêlo, ao invés de construirse molde comum a ambos os modelos, mediante a extração da média de dados comuns e, depois, proceder-se ao ajustamento específico, de acôrdo com as exigências do caso.

Dêsse modo, tem-se de trabalhar com a forma pura, com a categoria fundação, sintetizada em brevíssima definição - patrimônio personalizado dirigido a um fim -, não interessando os requisitos exigidos para sua existência, nem as formas de contrôle.

Passando-se à figura do contrato, o mesmo raciocínio. estará presente. Que é contrato? Um acôrdo de vontades. - Quando, porém, êsse acôrdo de vontades será de direito público ou de direito privado?

Os privatistas, novamente, imbuidos da elaboração romanistica, repelem a idéia do contrato de direito público, porque na transposição do molde civilístico para o setor publicístico a figura não se encaixa como uma luva. 
Ao invés de partirem do duorum pluviumve in idem placitum consensus para chegar ao minimo conceitual exigido - acôrdo contraposto de vontades que se encontram produzindo efeitos sôbre as partes - os privatistas entram nos elementos acessórios, passando a valorar a discussão das cláusulas, a possibilidade de alteração do pactuado por uma das partes, o desnivelamento econômico dos contratantes.

Raciocina-se, concluindo por exemplo, que "forçoso é reconhecer que um acôrdo que se despoja de seus elementos - tradicionais é bem pouco um contrato, se é que não deixa de sê-lo totalmente" ou "o contrato de direito público é vazio de sentido ou pura metáfora, ou ainda: "que significa um contrato que qualquer das partes pode desfazer, sem nenhuma conseqüência? - Cujas cláusulas podem ser modificadas, sem audiência da outra parte?"

Na realidade, discussão das cláusulas pelas partes, desigualdade econômica ou social dos contratantes, modificação - unilateral das cláusulas não são fatôres estranhos no âmbito do contrato de direito privado. $\mathrm{E}$ isso, entretanto, não altera a natureza da figura contratual.

A discussão das cláusulas contratuais inexiste nos contratos de adesão que celebramos a todo instante, ao ingressar numa casa de espetáculos, ao tomar um veículo; a desigualdade econômica verifica-se no campo do direito de trabalho quando o econômicamente fraco se filia à poderosa emprêsa; a modificação dos regulamentos de trabalho concretizam-se nessas mesmas organizações sem que se consultem os operários ou empregados.

Em que ficamos? Há um contrato de direito público? Há, mas não nos moldes estreitos do direito privado.

A investigação científica exige que se atinja a categoria contrato, que ultrapassa, sobrepairando, as modalidades específicas de um e de outro campo. A seguir o 
direito privado e o direito público, trabalhando com a forma contratual pura, poderão acrescentar-lhe os vários requisitos conotativos acessórios, que a flexionarão, matizando-a, no respectivo setor.

Este método científico de trabalho a ser observado na fixação das grandes linhas do direito público; o delineamento da forma pura, mediante análise do instituto, nos dois campos; a síntese conceitual através da eliminação do acessório e da retenção do essencial; o reingresso, num e noutro campo, com uma noção incomprometida, pronta a flexionar-se para atender às peculiaridades inconfundíveis do setor diversificado.

\section{Conclusão.}

$O$ direito é um só, tem uma finalidade única. $O$ público não se afasta de modo absoluto do privado a não ser em suas faixas extremas. Há um campus comum entre o direito público e o direito privado, dificilmente delimitado. A milenar colocação de Ulpiano, tolerável do ângulo didático, é aceita com inúmeras restrições pelos cientistas do direito, que procuram corrigir a deformação que o tempo produziu sôbre um dos ramos, que se desenvolveu, quase isolado, ao passo que outro está compensando a desvantagem, nestes últimos anos, em que é evidente o primado do direito público.

Em nossos dias, mercê da publicização do direito, è possível o levantamento, quase completo, de todos os institutos jurídicos, colocando-os, num quadro, frente a frente, aos pares, assinalando-se o número diminuto de ausência, no panorama geral, e procurando-se extrair das figuras, postas lado a lado, o máximo número de dados, que permite surpreender a categoria juridica, irradiada para os dois setôres. 
Só assim, evitando-se o errôneo método da transposição do privado para o público, será possível, dentro da inegável unidade monolítica do direito, conferir ao direito público, em geral, e ao direito administrativo, em particular, a relativa autonomia conquistada durante cem anos de ininterrupta atividade. 